\title{
Comparison of fish assemblages aggregated by artificial reefs using scuba diving and acoustic surveys
}

\author{
Hsueh-Jung Lu \\ National Taiwan Ocean University, Taiwan, ROC, hjlu@email.ntou.edu.tw \\ Jia-Rong Lin \\ National Taiwan Ocean University, Taiwan, ROC \\ Ting-Chieh Huang \\ National Taiwan Ocean University, Taiwan, ROC \\ Sunarti Sinaga \\ National Taiwan Ocean University, Taiwan, ROC
}

Follow this and additional works at: https://jmstt.ntou.edu.tw/journal

Part of the Fresh Water Studies Commons, Marine Biology Commons, Ocean Engineering Commons, Oceanography Commons, and the Other Oceanography and Atmospheric Sciences and Meteorology Commons

\section{Recommended Citation}

Lu, Hsueh-Jung; Lin, Jia-Rong; Huang, Ting-Chieh; and Sinaga, Sunarti (2021) "Comparison of fish assemblages aggregated by artificial reefs using scuba diving and acoustic surveys," Journal of Marine Science and Technology. Vol. 29: Iss. 2, Article 8.

DOI: $10.51400 / 2709-6998.1085$

Available at: https://jmstt.ntou.edu.tw/journal/vol29/iss2/8

This Research Article is brought to you for free and open access by Journal of Marine Science and Technology. It has been accepted for inclusion in Journal of Marine Science and Technology by an authorized editor of Journal of Marine Science and Technology. 


\title{
Comparison of Fish Assemblages Aggregated at Artificial Reefs by using Scuba Diving and Acoustic Surveys
}

\author{
Hsueh-Jung Lu ${ }^{a, c, *}$, Jia-Rong Lin ${ }^{a}$, Ting-Chieh Huang ${ }^{a, b}$, Sunarti Sinaga ${ }^{a}$

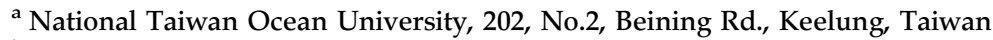 \\ ${ }^{\mathrm{b}}$ Marine Fisheries Division, Fisheries Research Institute, 199, He 1st Rd., Keelung, Taiwan \\ ${ }^{c}$ Center of Excellence for the Oceans, National Taiwan Ocean University, 202, No.2, Beining Rd., Keelung, Taiwan
}

\begin{abstract}
To determine the aggregation effect of artificial reefs (ARs), we conducted surveys in 16 artificial reefs in Taiwan by using the scientific echo sounder, Simrad EY-60 (200 KHz), along with sighting by scuba divers. Scuba diving was conducted within the reef structures $(r=20 \mathrm{~m})$, whereas acoustic surveys were conducted over a wider range $(r=100 \mathrm{~m})$, with five repeating transects over the ARs. We compared the results obtained from the two methods among 16 artificial reefs in the coastal waters of Taiwan to determine the consistency of the quantitative information between the two methods and to investigate the fish assemblage aggregation status of the ARs. The surveys were conducted in the summers of 2018 and 2019. In most cases, quantitative descriptors obtained by the acoustic surveys (e.g., TS, Sv, and NASC) and scuba diving (e.g., fish lengths and total number of fish) had consistency in variation. The mean fish length estimated by TS and scuba diving showed a synchronous change. The ARs with larger fish sighted by eye had larger fish detected by acoustics, and the ARs with higher diversity of aggregated fish had higher varia-tion of detected TS values. The consistency between the number of fish estimated by scuba diving and the NASC es-timated by acoustics are not as good as that of TS. A possible reason is that the acoustic surveying ranges are much wider than those of scuba diving and partly because the fish echoes were too close to the dead zone of the acoustic beam.
\end{abstract}

Keywords: Scientific echo sounder, Artificial reefs, Fish aggregation effect, Target strength

\section{Introduction}

$\mathrm{O}$ verfishing is one of the common threats to fishery resources all over the world in terms decrease in size and abundance, community destruction and even population extinction [5,2]. In addition to fishery management, deployment of artificial reefs (ARs), and implementation of fish conservation zones, offering habitat, refuge for breeding, and nursery ground for fishery resources, is an effective method to relieve overfishing $[3,4,12]$. In order to protect and prevent the collapse of fishery resources from overfishing, the Taiwanese government has been ac-tively deploying ARs in conservative fishery zones in the coastal waters since the 1970s [16] and [17]. According to the information available on the website of the Fisheries Agency, Council of Agriculture (https://www.fa.gov.tw/cht/Resource OtherZones/), up to the year 2018, there were a total of 89 AR sites located in 28 established fish conservative zones.

The ARs can increase the density, biodiversity, and size of fish during the functioning period after deployment. However, several years after 
deployment, the function of ARs will gradually decrease due to natural and anthropogenic forces, such as by burial, collapse, destruction, or entanglement by fishing nets. To maintain, improve or abandon the ARs, it is important to investigate and evaluate the condition of ARs on a timely basis. In addition to fishery-dependent data, mainly catch statistics, fishery-independent surveys are also essential because some SAR waters are prohibited from fishing operations. Scuba diving is generally the major method for gathering information on the condition and function of ARs, which provides information of high credibility because seeing is believing. However, due to time and depth constraints, scuba diving is difficult to be conducted in the entire AR area. Scuba diving surveys generally adopt a line transect survey method with limited distance, depth, and time.

Acoustic surveys with direct, three-dimensional, fast, and non-destructive characteristics is a convenient and objective method [10,14,11], which can be used in AR surveys. A number of studies have used echosounders to quantitatively and qualitatively evaluate ARs in various seas around the world [6] and [7]. However, few of them can confirm the validity of acoustic data for surveys in AR areas. In this study, we de-signed 16 joint surveys of acoustic and scuba diving in different ARs in Taiwan to determine how close the acoustic survey data are to the actual fish schools and discuss the interpretation of acoustic data.

\section{Material and Method}

We selected 16 ARs in eight fish conservation zones with half of them in the northern region and half of them in the southern coastal area of Taiwan (Fig. 1). Table 1 shows the basic information of the ARs, including material and type, location, the year it had been deployed, bottom depth, and reef height.

For each AR in Table 1, we designed a joint scuba diving and acoustic survey. The duration of each scuba diving sur-vey was about 30 minutes within a range of 20 meters around the AR. The observation was mainly by photography, and visual observation records. Three to four divers, as a group, observed and recorded samples in a waterproof record book. The data items recorded were the species and

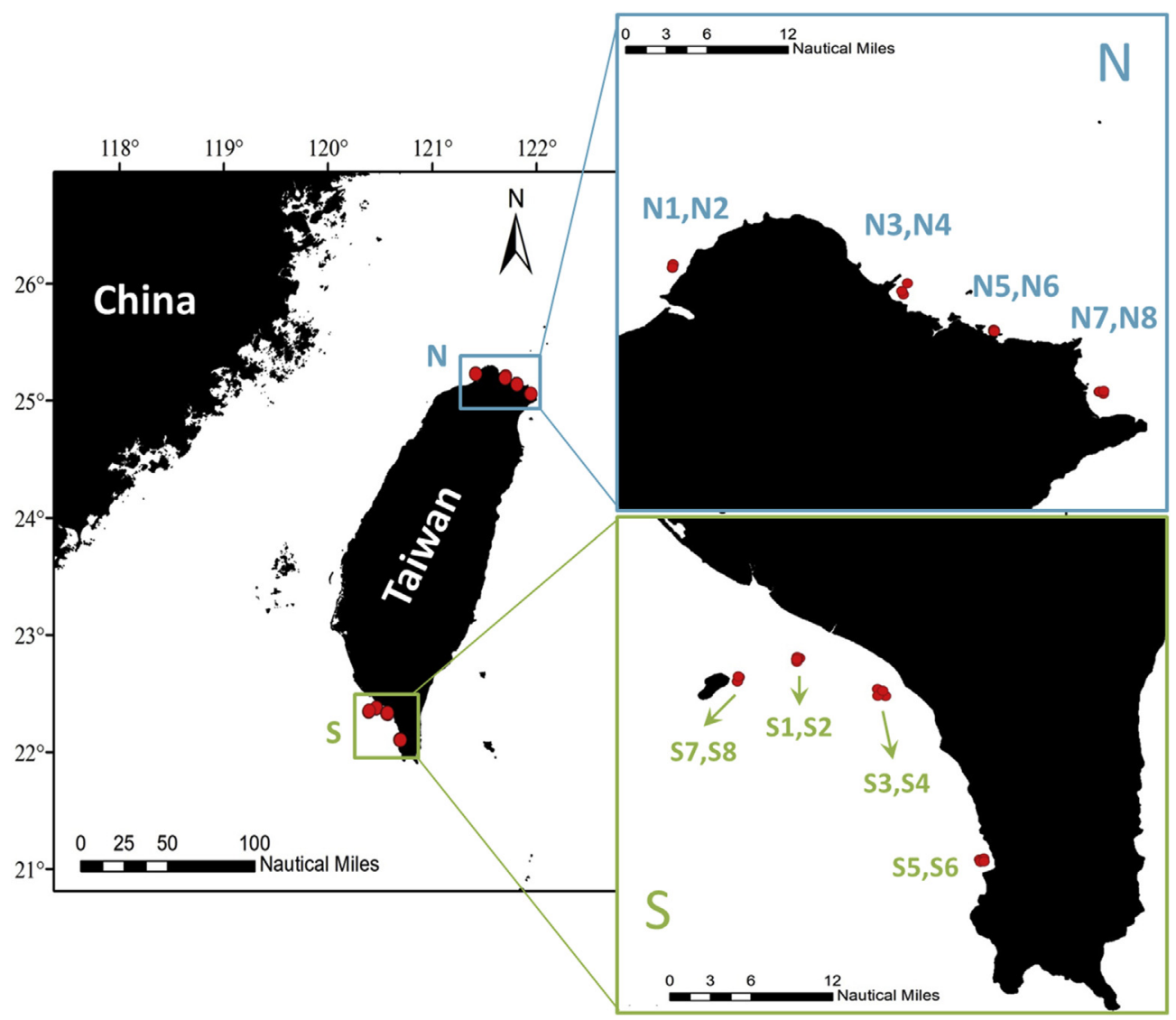

Fig. 1. Locations of the 16 selected artificial reefs for acoustic and scuba diving survey in this study. 
Table 1. Basic information of the artificial reefs surveyed in this study with 8 in north and 8 in south Taiwan. The information of the total number of reefs, bottom depth and reef height were updated by scuba diving during this study.

\begin{tabular}{llllllll}
\hline Reef & Name & Material and Type & Location $($ Lon/Lat) & Year of deploy & Total number & Bottom depth $(\mathrm{m})$ & Reef height $(\mathrm{m})$ \\
\hline N1 & Tanshui & Steel frame & $121^{\circ} 24.997^{\prime} \mathrm{E} / 25^{\circ} 13.989^{\prime} \mathrm{N}$ & 2013 & 1 & 31 & 5.4 \\
N2 & Tanshui & Telephone pole & $121^{\circ} 24.939^{\prime} \mathrm{E} / 25^{\circ} 13.704^{\prime} \mathrm{N}$ & 2004 & 50 & 27 & 5 \\
N3 & Wanli & Steel frame & $121^{\circ} 41.884^{\prime} \mathrm{E} / 25^{\circ} 11.801^{\prime} \mathrm{N}$ & 2010 & 3 & 27.7 & 5.3 \\
N4 & Wanli & Steel frame & $121^{\circ} 41.991^{\prime} \mathrm{E} / 25^{\circ} 11.514^{\prime} \mathrm{N}$ & 2012 & 3 & 26.9 & 5.8 \\
N5 & Auti & Concrete block & $121^{\circ} 56.446^{\prime} \mathrm{E} / 25^{\circ} 03.579^{\prime} \mathrm{N}$ & 1990 & 40 & 30 & 3.8 \\
N6 & Auti & Telephone pole & $121^{\circ} 56.773^{\prime} \mathrm{E} / 25^{\circ} 03.416^{\prime} \mathrm{N}$ & 2002 & 150 & 27.5 & 4.5 \\
N7 & Wanhaixiang & Telephone pole & $121^{\circ} 48.661^{\prime} \mathrm{E} / 25^{\circ} 08.636^{\prime} \mathrm{N}$ & 2003 & 100 & 30.2 & 3.4 \\
N8 & Wanhaixiang & Research vessel & $121^{\circ} 48.669^{\prime} \mathrm{E} / 25^{\circ} 08.485^{\prime} \mathrm{N}$ & 2012 & 1 & 27.8 & 7 \\
S1 & Linbien & Fishing boat & $120^{\circ} 28.050^{\prime} \mathrm{E} / 22^{\circ} 22.592^{\prime} \mathrm{N}$ & 2006 & 1 & 24.4 & 10.8 \\
S2 & Linbien & Steel frame & $120^{\circ} 27.877^{\prime} \mathrm{E} / 22^{\circ} 22.696^{\prime} \mathrm{N}$ & 2005 & 1 & 30.9 & 5.2 \\
S3 & Fanliao & Steel frame & $120^{\circ} 34.381^{\prime} \mathrm{E} / 22^{\circ} 19.511^{\prime} \mathrm{N}$ & 2011 & 1 & 28.6 & 5.4 \\
S4 & Fanliao & Steel frame & $120^{\circ} 33.782^{\prime} \mathrm{E} / 22^{\circ} 20.085^{\prime} \mathrm{N}$ & 2012 & 2 & 28.4 & 7.6 \\
S5 & Haiko & War ship & $120^{\circ} 41.304^{\prime} \mathrm{E} / 22^{\circ} 06.225^{\prime} \mathrm{N}$ & 2015 & 1 & 47.6 & 21.1 \\
S6 & Haiko & Telephone pole & $120^{\circ} 41.620^{\prime} \mathrm{E} / 22^{\circ} 06.313^{\prime} \mathrm{N}$ & 2002 & 10 & 33.4 & 7.5 \\
S7 & Xiaoliuchiu & Fishing boat & $120^{\circ} 23.603^{\prime} \mathrm{E} / 22^{\circ} 21.057^{\prime} \mathrm{N}$ & 1992 & 1 & 29.7 & 4.9 \\
S8 & Xiaoliuchiu & Steel frame & $120^{\circ} 23.466^{\prime} \mathrm{E} / 22^{\circ} 20.707 \mathrm{~N}$ & 2012 & 2 & 32.2 & 5.2 \\
\hline
\end{tabular}

number of fish, by which the total estimated number, diversity index $\left(\mathrm{H}^{\prime}\right)$ [15], and evenness index $\left(\mathrm{J}^{\prime}\right)$ [13] for each AR were determined. The $\mathrm{H}^{\prime}$ and $\mathrm{J}^{\prime}$ values of an AR indicate the nature-logarithm of the effective number of fish species and the possibility of it being the same species when locating two fishes, respectively. Scuba divers also conducted a visual estimation of the fish length of each species.

Acoustic surveys were carried out simultaneously while scuba diving was conducted. As shown in Fig. 2, there were five repeating transects with a length of $200 \mathrm{~m}$ over the ARs while conducting the scuba diving survey. The acoustic system is a Simrad EY-60 echosounder, and the parameters are listed in Table 2 . The speed of the survey vessel was approximately about 3-4 knots.

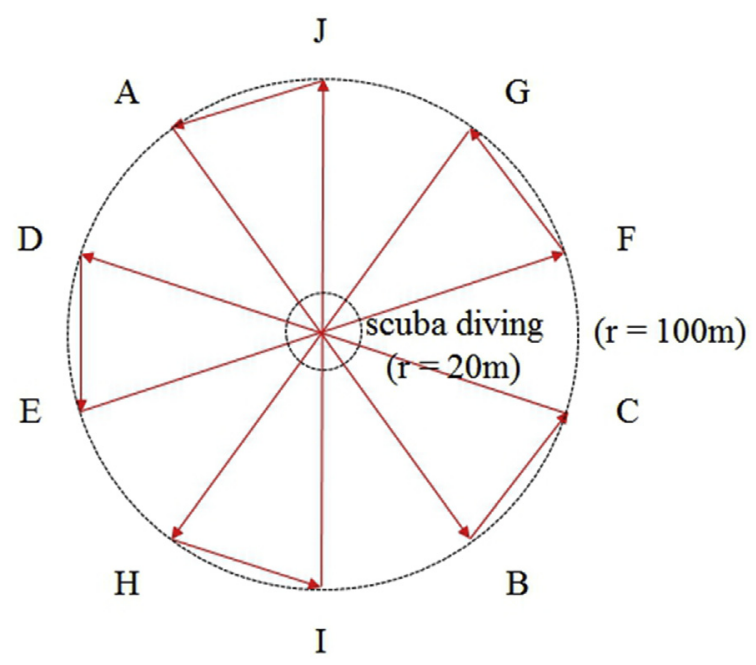

Fig. 2. Special acoustic trackline designed for repeating 5 passes on the top of an artificial reef during scuba diving observation.
We used the post-processing software Myriax Echoview to process the collected echo data. The acoustic data were analyzed to detect single targets using the fish track function pro-vided by Echoview. The parameter settings for single-target detection are shown in Table 2. Fish tracks were extracted only if the number of consecutive single targets were higher than three. Only the target strengths (TS) from the extracted fish tracks were considered as fish presence in the AR, which were computed to average $\mathrm{TS}$ and then converted to approximate fish length by the equation created by [8]; in which the dorsal-aspect TS of a number of individual teleostean fishes of eight species were measured at various frequencies.

Table 2. Parameter settings of the scientific echo sounder system (Simrad EY60) used for acoustic survey in artificial reefs and filtering parameters for detecting single targets.

\begin{tabular}{ll}
\hline Parameter & Value \\
\hline Ping interval (ping/s) & 10 \\
Frequency (KHz) & 200 \\
Absorption coefficient (dB/m) & 0.0776 \\
Sound Velocity (m/s) & 1543.41 \\
Transducer gain (dB) & 25.56 \\
Transmitted pulse length (ms) & 0.256 \\
Power (W) & 100 \\
Two-Way beam factor (dB re 1sr) & -20.7 \\
Minor axis 3 dB beam angle (degree) & 7 \\
Major axis 3 dB beam angle (degree) & 6.62 \\
Minor axis 3 dB offset angle (degree) & -0.02 \\
Major axis 3 dB offset angle (degree) & -0.14 \\
Single target detection & \\
Minimum TS threshold (dB) & -50 \\
Minimum echo length ratio with pulse duration & 0.8 \\
Maximum echo length ratio with pulse duration & 1.8 \\
Maximum phase deviation & 8 \\
Maximum gain compensation (dB) & 6 \\
Minimum echo spacing & 1 \\
\hline
\end{tabular}


$\mathrm{TS}=19.1 \log \mathrm{L}-34.3124$

where TS is for frequency of $200 \mathrm{kHz}$ and $\mathrm{L}$ is length of fish $(\mathrm{cm})$.

Echo data of water columns shallower than $3 \mathrm{~m}$ were excluded because they were susceptible to bubbles and noise interferences from the ship. Nonbiological echoes, such as those from gill nets and bubbles from the divers, were excluded manually. The volume backscattering strength (Sv) of each elementary sampling distance unit (ESDU), defined as $20 \mathrm{~m}$ by GPS distance and whole water column (from $3 \mathrm{~m}$ below the surface to the sea bottom), is then calculated. The average volume backscattering within the buffer range of an $\operatorname{AR}(r=100 \mathrm{~m})$ is determined from all the ESDUs of the five tracklines using the following equation:

$$
\overline{S v}=10 \log \left(\frac{\sum_{i=1}^{n} \gamma_{i} 10^{\frac{S V_{i}}{10}}}{\sum_{i}^{n} \gamma_{i}}\right)
$$

\section{i: index of ESDU}

$\mathrm{n}$ : total number of ESDU

$\gamma_{i}$ : if 0 for the ESDU without samples, otherwise 1

$\mathrm{Sv}_{\mathrm{i}}:$ mean $\mathrm{Sv}$ in each ESDU

Sv: mean Sv of all ESDU

The $\overline{S v}$ were then converted to Nautical Area Scattering Coefficient (NASC) using the following formula to represent the index of total biomass aggregated at an AR:

$\mathrm{NASC}=4 \pi \times 1852^{2} \times T \times 10^{\overline{\mathrm{Sv}}}$

$4 \pi$ : steradians in a sphere - converting "backscattering" cross-section to "scattering" cross-section

1852: meters per nautical mile $(\mathrm{m} / \mathrm{nmi})$
Sv: mean volume backscattering strength of the domain being integrated $\left(\mathrm{dB}\right.$ re $1 \mathrm{~m}^{2} \mathrm{~m}^{-3}$ )

$\mathrm{T}$ : mean thickness of the domain being integrated

\section{Results}

\subsection{Scuba diving}

Table 3 shows the descriptors of fish assemblages observed by scuba diving in the 16 ARs, including species numbers, total number, diversity index $\left(\mathrm{H}^{\prime}\right)$, and evenness index $\left(\mathrm{J}^{\prime}\right)$. The status of aggregated fish assemblages indicated by these descriptors differ greatly and has no simple relationship with the place, materials, type, total number, depth, height, and setting year of the ARs (Table 1).

Figs. 3 and 4 provide a quick comparison between the fish size and abundance among the 16 ARs, estimated by scuba diving, respectively. As shown in Fig. 3, of the eight northern ARs, fish size observed in N5-N7 were relatively larger than that of the others. Of the eight southern ARs, fish size observed in S5-S7 were relatively larger than that of the others. As for the total number of fish estimated by scuba diving (Fig. 4), two ARs had a very high abundance of fish. The highest number of fish observed was in the Wanli Reef (N3), which consists of three steel frame reefs. The estimated total number of fish aggregated at the AR was 11,472, but $88 \%$ of them were of small fish species, Ostorhinchus semilineatus, with a length of about $5 \mathrm{~cm}$. The lowest $\mathrm{H}^{\prime}$ with the second highest number of fish was in Xiaoliuchiu Reef (S8), with an estimated total number of fish of 5,644 , and $89 \%$ of them were also a small fish species, Rhabdamia gracilis, with a length of about $4 \mathrm{~cm}$.

Table 3. Estimated number of fish, diversity index $\left(H^{\prime}\right)$ and evenness index $\left(J^{\prime}\right)$ by scuba diving survey in each artificial reef.

\begin{tabular}{llllll}
\hline Reef & Date of survey & Species & Estimated number & Diversity index $\left(\mathrm{H}^{\prime}\right)$ & Evenness index $\left(\mathrm{J}^{\prime}\right)$ \\
\hline N1 & 20180807 & 12 & 541 & 1.81 & 0.73 \\
N2 & 20180807 & 11 & 437 & 1.78 & 0.71 \\
N3 & 20180731 & 28 & 11472 & 0.62 & 0.19 \\
N4 & 20180731 & 32 & 2123 & 1.93 & 0.56 \\
N5 & 20180727 & 46 & 247 & 3.30 & 0.86 \\
N6 & 20180727 & 49 & 409 & 2.92 & 0.75 \\
N7 & 20180730 & 25 & 735 & 1.74 & 0.54 \\
N8 & 20180730 & 32 & 1566 & 2.17 & 0.63 \\
S1 & 20190611 & 22 & 479 & 1.76 & 0.57 \\
S2 & 20190611 & 7 & 220 & 1.19 & 0.61 \\
S3 & 20190723 & 12 & 372 & 0.91 & 0.37 \\
S4 & 20190723 & 22 & 463 & 1.51 & 0.49 \\
S5 & 20190610 & 26 & 641 & 2.00 & 0.60 \\
S6 & 20190610 & 42 & 1380 & 2.25 & 0.60 \\
S7 & 20190612 & 32 & 1066 & 1.51 & 0.40 \\
S8 & 20190612 & 5644 & 0.49 & 0.14 \\
\hline
\end{tabular}



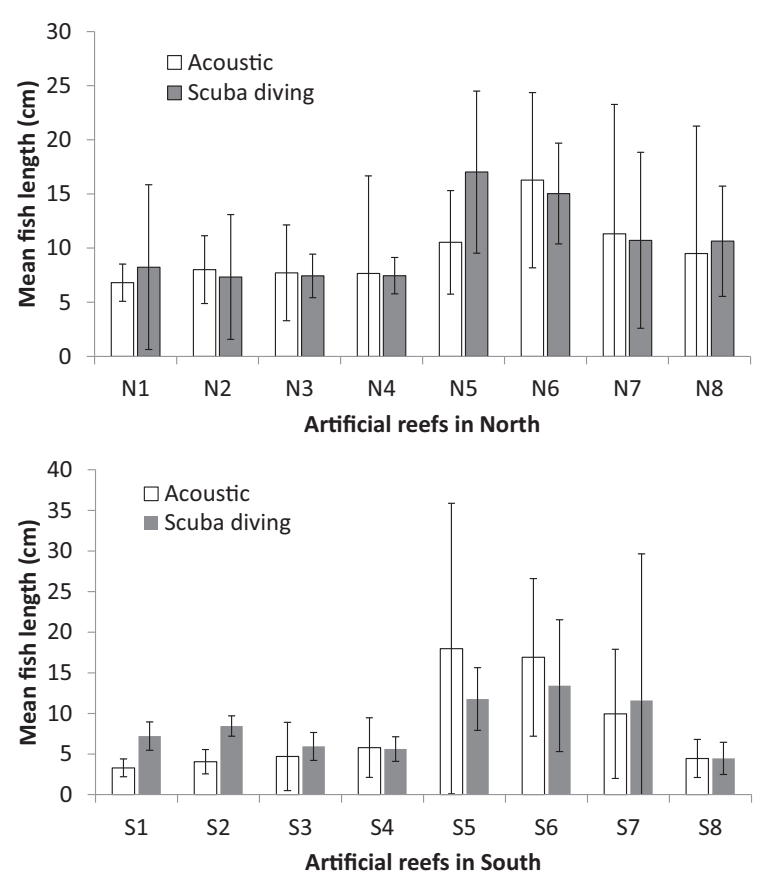

Fig. 3. Mean and standard deviation of fish size (cm) estimated by TS and by scuba diving observation in each artificial reef.
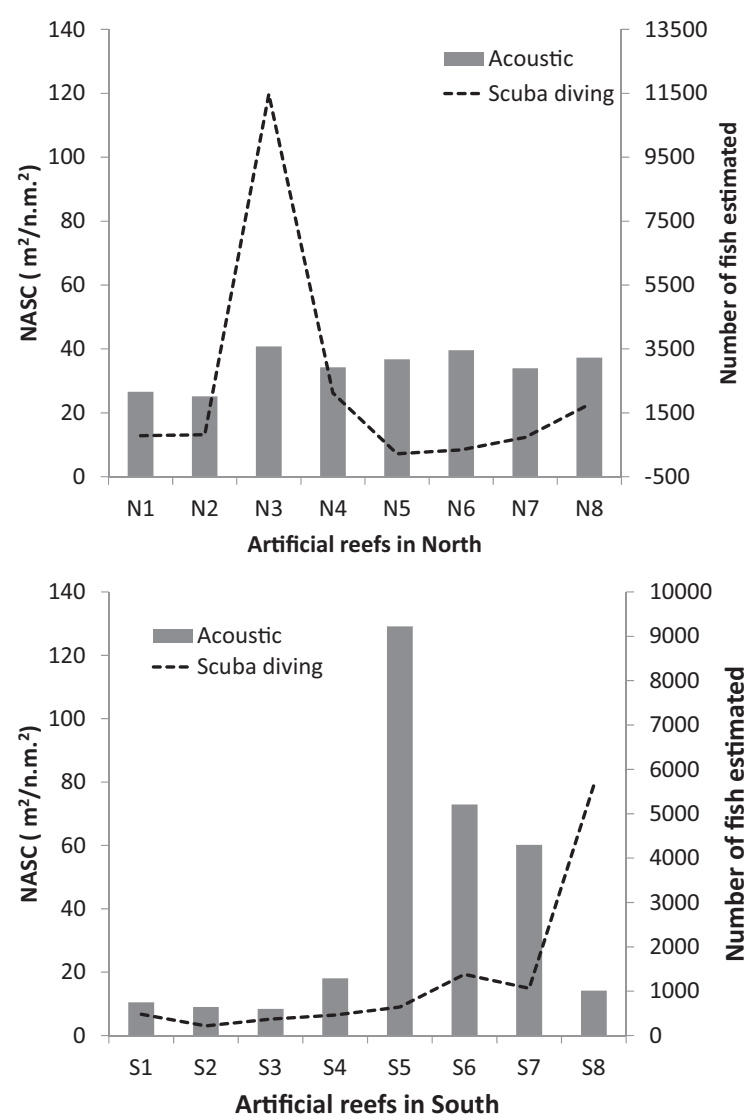

Fig. 4. Number of fish aggregated in the artificial reefs estimated by scuba diving observation and NASC estimated by acoustic survey within $100 \mathrm{~m}$ from the center of the reef.

\subsection{Acoustic survey}

During the acoustic survey of the ARs mentioned in Table 1, each AR had five acoustic detections while the scuba diving survey was carried out. Fig. 5 shows a few examples of small portions of the original echograms before it was post-processed by Echoview. We can get a brief impression of the fish aggregation conditions of each AR from the original echograms. However, quantitative description of the fish aggregation condition of each AR depends on the quantified $\mathrm{Sv}$ and TS values.

Fig. 6 shows the contour map of the Sv values and aver-age TS along the tracklines. The contour map of $S v$ values in the buffer area $(r=100 \mathrm{~m})$ of an AR were interpolated with the Sv of each ESDU using the kriging method (Surfer 9.0, Golden Software Inc.). For most of them, the area close to the scuba diving area of the AR had higher Sv values, which means that fish assemblages are mostly associated with the AR. Some of them relatively had no high Sv near the AR, such as N1, N5, S1, S2, and S3, indicating that the fish aggregation effect by AR was not significant. In the N6 and S5 ARs, fish assemblages were not concentrated near the AR but dispersed in a wider range.

Fig. 4 shows the NASC of each AR calculated by Equation (3). In the eight ARs in the north, the NASC remained almost constant with no particular low or high values $($ mean $=34.3$; S.D. $=5.7$ ). However, in the 8 ARs in the south, the NASC were polarized, and S5-S7 had very high values, while the others had very low values (mean $=40.3$; S.D. $=43.7)$.

\subsection{Comparison between acoustic and scuba diving}

The average value of the TS for each AR in Fig. 6 was transformed into fish length by Equation (1) and compared with the lengths estimated by scuba diving (Fig. 3). The mean values of fish lengths estimated by acoustic survey were mostly consistent with the mean values of fish length observed by scuba diving. The TS of fish tracks detected by echosounder within a $100 \mathrm{~m}$ range from the AR can represent the fish assemblages associated with the ARs.

The values of NASC for the eight ARs in northern Taiwan were evenly distributed (Fig. 4). The abundance estimated by scuba diving was also evenly distributed, except for the AR N3; the estimated number of fish for AR N3 by scuba diving was 11,472 , while the average total number of fish for the other seven ARs was 970. Unlike the NASC of the 


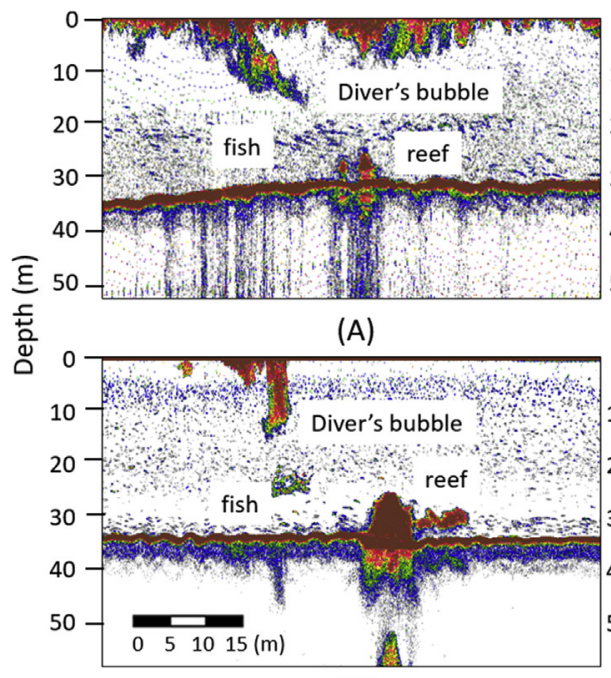

(C)

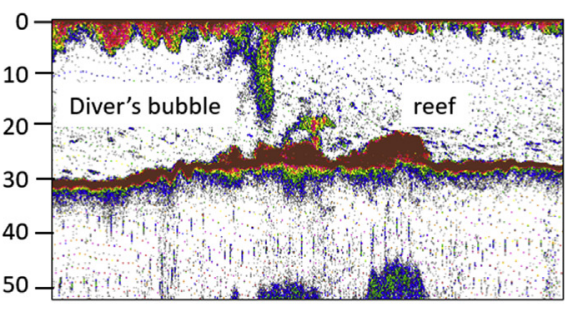

(B)

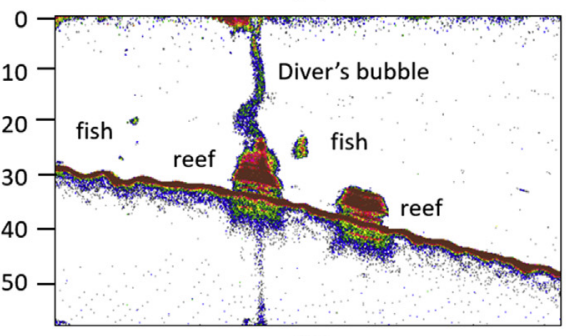

(D)

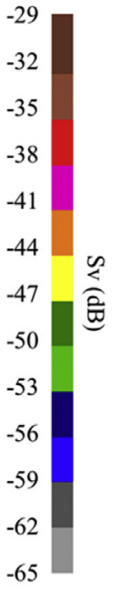

(20)

Fig. 5. Examples of echogram with acoustic transects passing over an artificial reef. (A) Tanshui steel frame reef (N1), (B) Tanshui telephone pole reef (N2), (C) Fanliao steel frame reef (S4), (D) Xiaoliuchiu steel frame reef (S8).

northern ARs, the eight ARs in the south were not evenly distributed. S5-S7 had higher NASC values than the others and relatively higher total fish numbers estimated by scuba diving. In general, except for AR S8, the ARs with relatively high aggregated abundance estimated by scuba diving agreed with that estimated by acoustic surveys. In contrast, the highest number of fish estimated by scuba diving was in the AR S8, but the NASC value was low.

\section{Disscussion and Conclusion}

Scientific echo sounder and scuba diving are two common ways to collect quantitative information of marine organisms in ARs or other coastal fishery facilities. The former is faster, has a wider range, and easy working conditions, but the latter is slow, has a narrow range, and strict working conditions determined by currents, transparency, depth, etc. On one hand, the former can provide quantitative information of the standing crop for fishery resources through random sampling in the broad sea, which is beyond what the latter can collect in the same space and time. On the other hand, the latter can provide detailed information of the physical and biological condition of ARs that the former cannot offer. The two survey methods can work independently to collect their own specific information in AR waters. However, there has been no experiments or studies comparing the survey results of the two methods to confirm the validity of acoustic data for AR. In this study, we carried out 16 joint surveys combining acoustic and scuba diving in different
ARs in the northern and southern coastal waters of Taiwan. After comparing the results from both acoustic and scuba diving, we are able to know how close the acoustic survey data are to the actual fish schools, which would enable the reliability of the interpretation of acoustic data. In most cases, quantitative descriptors obtained by acoustic (e.g., TS, Sv, and NASC) and scuba diving (e.g., fish lengths, total number of fish), had consistency in variation.

The first commonly used quantitative descriptor of acoustic survey is the TS of a single target. To segregate non-fish tar-gets, we extracted fish tracks as fish, only if the number of consecutive single targets was higher than three [9]. The estimated fish lengths were computed from the average TS of fish tracks using Equation (1). In general, the variations in the mean fish lengths estimated by TS and scuba diving were synchronous (Fig. 3); the ARs with larger fish sighted by eye had larger fish lengths estimated by acoustic. The ARs with higher variation (S.D.) of estimated fish length, such as N5, N6, N8, S6, S7, etc., took place in the ARs with higher fish diversity (higher $\mathrm{H}^{\prime}$ or lower $\mathrm{J}^{\prime}$ ) (Table 3). The ARs with higher diversity of aggregated fish had higher variations in detected TS values and transformed lengths by Equation (1).

The second commonly used quantitative descriptor is echo integration output such as Sv and NASC. The consistency between the number of fish estimated by scuba diving and the NASC estimated by acoustic are not as good as that of TS. One possible reason is that the acoustic surveying ranges 


\section{North}
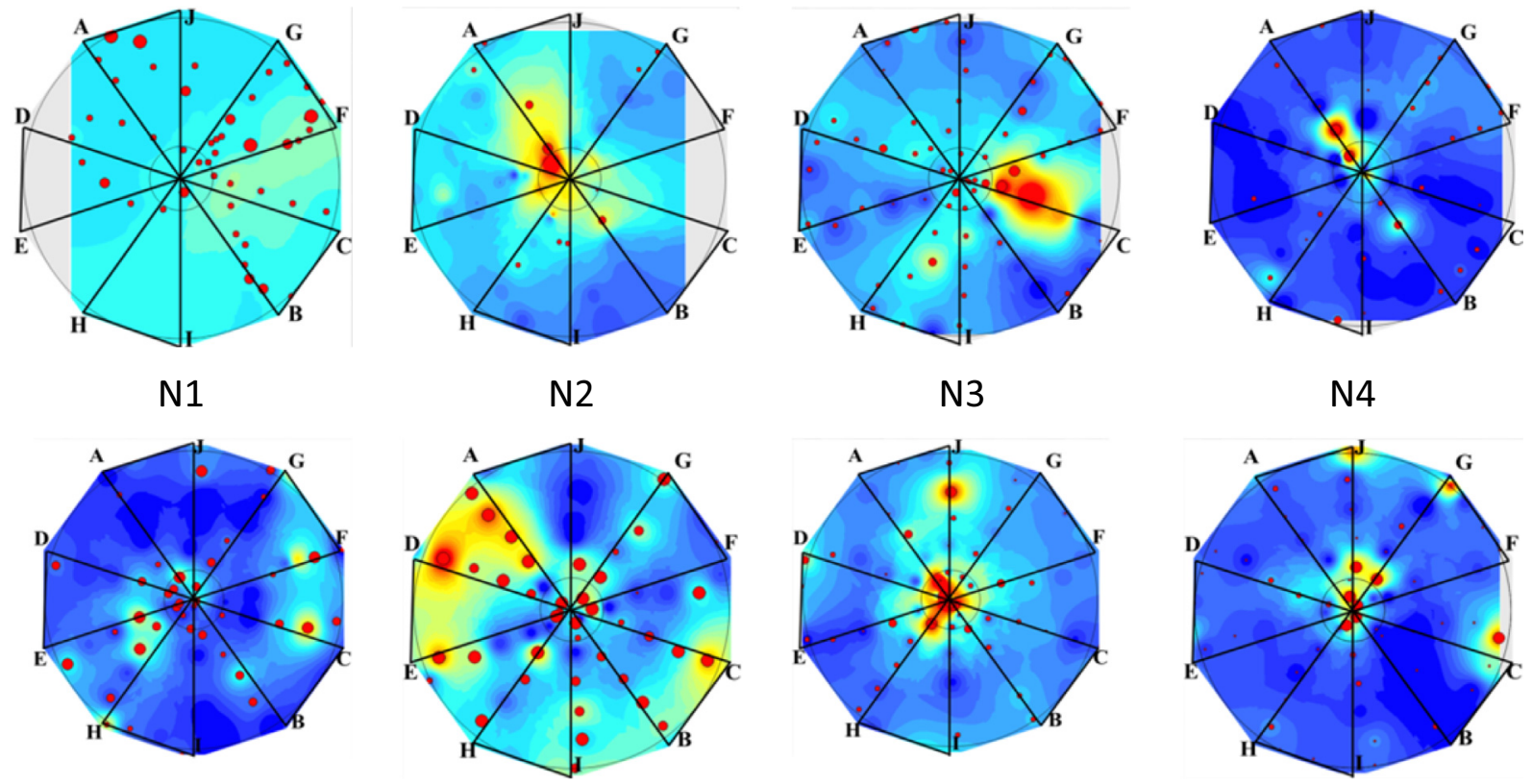

N3

N4

N5

N6

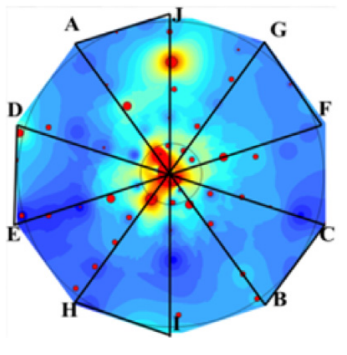

N7

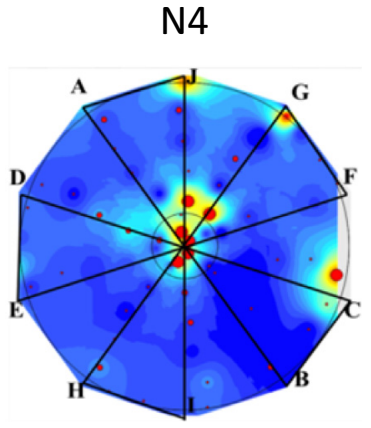

N8

\section{South}

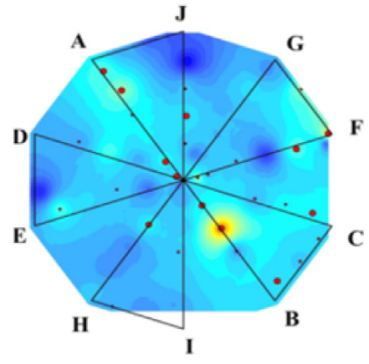

S1

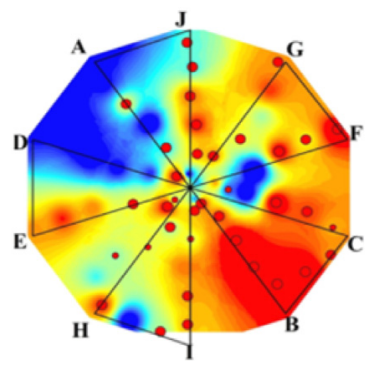

S5

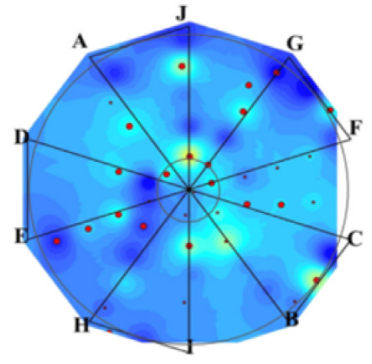

S2

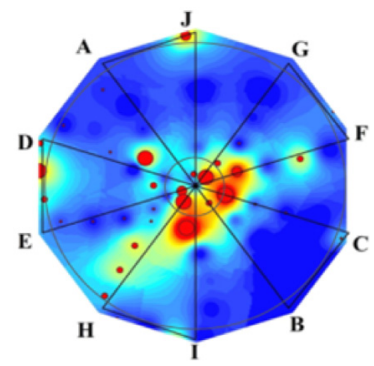

S6

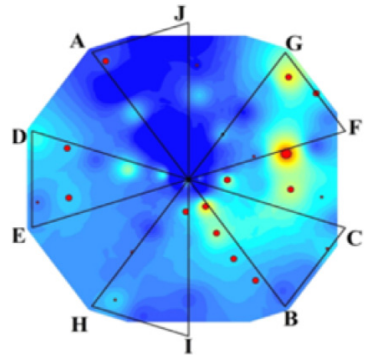

S3

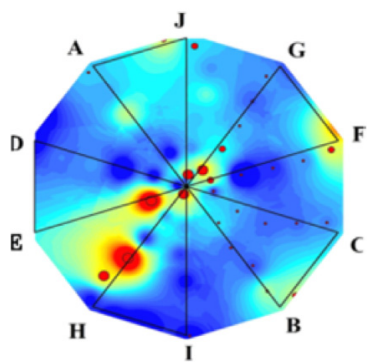

S7

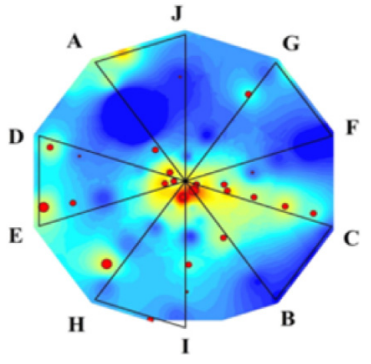

S4

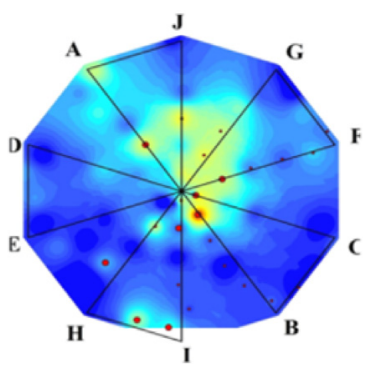

S8

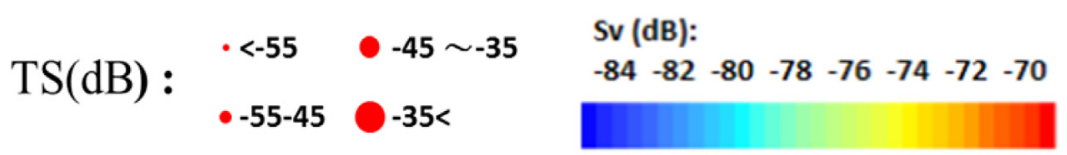

Fig. 6. Target strengths and volume backscattering strength (Sv) distribution obtained by acoustic survey. 
are much wider than those of scuba diving (Figs. 2 and 6). The scuba divers estimated fish abundance based only on their visual range which is less than that of the acoustic surveys. Most of the fish assemblages were aggregated near the center of the AR where scuba diving was carried out (Fig. 6), but some of them were located more than $20 \mathrm{~m}$ away from the AR (N3, N6, S5, S7). Furthermore, the two ARs with the highest discrepancy between scuba diving and acoustic are N3 and S8. Scuba diving estimated peak values of fish abundance, but acoustic NASC remained at an average level. This discrepancy may be because the fish echoes of fish recorded by divers were too close to the dead zone of the acoustic beam and were therefore unable to be distinguished from the reef body or sea bottom.

In order to perform a comparison between acoustic and scuba diving, the 16 surveys in different ARs were completed within approximately 1.5 hours. The two survey methods were carried out simultaneously in the limited waters surrounding the AR. The value of the degree of coverage (DOC) of the acoustic survey was 7.3, which is higher than the suggested value of 6 [1]. The actual distribution or effective range of an AR may be wider than what we designed for this study, and the DOC can be lower for future acoustic surveys.

The status of the fish aggregation effect of the 16 ARs differed greatly in terms of species and abundance [16] and [17]. Figs. 3 and 4 provide a basic evaluation of their fish aggregation function. The ARs in the north showed better performance in both NASC and estimated fish lengths than those of the south. S1-S4 are the four poorest performance ARs by both acoustic and scuba diving surveys. The factors resulting in poor performance of the aggregation effect are very complicated. We are unable to conclude the exact reasons based on the limited information obtained in this study. However, it would be nothing more than natural decay due to physical or chemical effects and anthropogenic destruction by fishing or illegal fishing.

\section{Acknowledgement}

This study was supported by the Fisheries Agency, Council of Agriculture (C0720426 and
C0820222) and the Ministry of Science, Taiwan and Technology (MOST 108-2611-M-019 -001 -), Taiwan.

\section{References}

[1] Aglen A. Random errors of acoustic fish abundance estimates in relation to survey grid density applied. FAO Fish Rep 1983;300:293-8.

[2] Bellwood DR, Hoey AS, Choat JH. Limited functional redundancy in high diversity systems: resilience and ecosystem function on coral reefs. Ecol Lett 2003;6(4):281-5.

[3] Charbonnel E, Serre C, Ruitton S, Harmelin JG, Jensen A. Effects of increased habitat complexity on fish assemblages associated with large artificial reef units (French Mediterranean coast). ICES J Mar Sci 2002;59:S208-13.

[4] Fernandes L, Day J, Lewis A, Slegers S, Kerrigan B, Breen D. Establishing representative no-take areas in the Great Barrier Reef: large-scale implementation of theory on marine protected areas. Conserv Biol 2005;19(6):1733-44.

[5] Jackson JB, Kirby MX, Berger WH, Bjorndal KA, Botsford LW, Bourque BJ. Historical overfishing and the re-cent collapse of coastal ecosystems. Sciences 2001;293(5530):629-37.

[6] Kang M, Nakamura T, Hamano A. A methodology for acoustic and geospatial analysis of diverse artificial reef data sets. ICES J Mar Sci 2011;68(10):2210-21.

[7] Kang M, Fajayanti R, Jung B, Yoon E, Min E, Lee K, et al. Fishes distribution and their connection to artificial reefs off Bukchon, Jeju Island using geographic information system. Journal of the Korean Society of Fisheries and Ocean Technology 2019;55(2):121-8.

[8] Love RH. Dorsal-aspect target strength of an individual fish. The J Acoust Soc Am 1971;49(3B):816-23.

[9] Lu HJ, Kang M, Hunag HH, Lai CC, Wu LJ. Ex situ and in situ measurement of juvenile yellowfin tuna Thunnus albacares target strength. Fish Sci 2011;77:903-13.

[10] MacLennan D. Acoustical measurement of fish abundance. The J Acoust Soc Am 1990;87(1):1-15.

[11] Ohshimo S. Acoustic estimation of biomass and school character of the Japanese anchovy Engraulis japonica in the East China Sea and the Yellow Sea. Fisheries Science 1996; 62(3):344-9.

[12] Perkol-Finkel S, Benayahu Y. Differential recruitment of benthic communities on neighboring artificial and natural reefs. J Exp Mar Biol Ecol 2007;340:25-39.

[13] Pielou EC. The measurement of diversity in different types of biological collections. J Theor Biol 1966;13:131-44.

[14] Rose GA. A review of problems and new direction in the application of fisheries acoustics on the Canadian East Coast. Fish Res 1992;14(2-3):105-28.

[15] Shannon CE. A mathematical theory of communication. Bell Sys Tech J 1948;27:379-423. 623-656.

[16] Shao KT, Lu HJ, Huang JS, Chen TJ, Lin SM, Wu SP. Biological survey in artificial reefs and aquatic breeding and protection zones in northern Taiwan. 2018 project report of Fisheries Agency. Council of Agriculture; 2018. p. 219 (in Chinese).

[17] Shao KT, Lu HJ, Huang JS, Chen TJ, Lin SM, Wu SP, et al. Biological survey in artificial reefs and aquatic breeding and protection zones in northern Taiwan. 2019 project report of Fisheries Agency. Council of Agriculture; 2019. p. 219 (in Chinese). 